\title{
Chapter 1 \\ Unfolding the Educational and Practical \\ Resources Inherent in Mathematics for \\ Teaching Mathematics
}

\author{
This: Combining thinking and doing \\ This: Inducing students to combine thinking and doing \\ is the source point of any productive education.
}

Friedrich Froebel 1821

The objective of this introductory chapter is to explain the common rationale behind the papers of this volume. The structure is as follows.

The first section shows that learning environments are a natural way to address teachers in their main role, teaching, and that therefore this approach is promising for improving mathematics teaching in an effective way. The section ends with a teaching model based on Guy Brousseau's theory of didactical situations.

The second section illustrates how in a concrete case the general terms in this teaching model can be brought to life by drawing from processes inherent in mathematics.

The general principles behind this special case are explained in the third section. It will turn out that they arise from a genetic view of mathematics.

The fourth section deals with the consequences for teacher education that result in demanding special mathematical courses for teachers.

\section{From "Instruction and Receptivity" to "Organization and Activity" in Teaching}

In 1968 the journal Educational Studies in Mathematics (founded by Hans Freudenthal) started with the papers presented at a conference on "How to teach mathematics so as to be useful?" One year later, after two years of teaching at the gymnasium and four years in mathematical research, the present author moved to mathematics education and saw himself confronted with huge challenges in teacher education. 
This led him to the following question: "How to teach teachers so as to be useful for teaching mathematics so as to be useful?"

The main professional task of a teacher is to prepare, conduct, analyze lessons and mark papers, and the success of teaching crucially depends on getting students actively involved, not by applying extrinsic means of motivation but by applying intrinsic ones. So, it seems a logical decision to develop mathematics education in a way that makes sense at the very front of teaching. This has completely been in line with the position expressed by Richard Elmore (1997):

"What do I teach on Monday morning?" is the persistent question confronting teachers. Because they are inclined to ask such questions, teachers are often accused by researchers, reformers, and policymakers of being narrow and overly practical in their responses to the big ideas of education reform. Given the state of the current debate on standards-based reform, though, I think the Monday morning question is exactly the right one, and it should be firmly placed in the minds of everyone who purports to engage in that reform.

Consider the following practical issues. Most statements of content and performance standards coming from professionals and policymakers take no account whatsoever of such basic facts as the amount of time teachers and students have in which to cover content. They are merely complex wish lists. In order to be useful in answering the Monday morning question, they have to be drastically pared, simplified, and made operational in the form of lesson plans, materials, and practical ideas about teaching practice.

Mutatis mutandis this statement also refers to present research in mathematics education.

For centuries the professional frame of teachers has been described as the "didactic triad" (Fig. 1) or in a somewhat extended version as the "didactic tetrahedron" (Fig. 2).

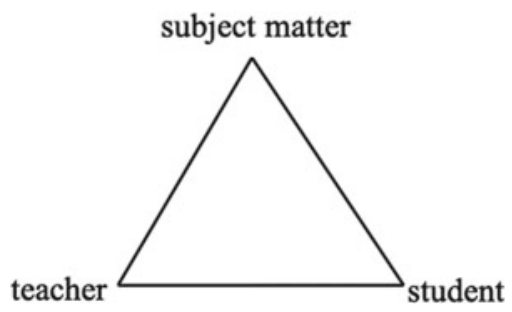

Fig. 1 Didactic triad

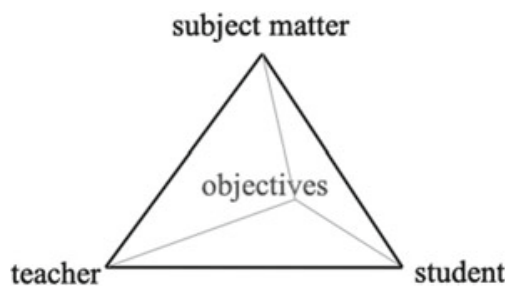

Fig. 2 Didactic tetrahedron 
Up to the end of the nineteenth century and into the first decades of the twentieth century the role of the teacher was widely understood as that of an "instructor" or "deliverer of knowledge". His or her task was to separate pieces of subject matter, present it to the students, link it to what they had learned before, embed it into a system and test if the students could reproduce and apply the new knowledge.

The most elaborate form of this view on teaching and learning are the famous "formal stages" by Friedrich Herbart that were elaborated for the teaching practice by his successors. Wilhelm Rein gave them their final form: "Preparation", "Presentation", "Association", "System", and "Application" (for details see de Garmo 2001, Chap. V, 130 ff.).

At the beginning of the twentieth century the "progressive education" movement gave new impetus to voices who had been pleading in favor of a shift for a long time. In 1916 the German mathematics educator Johannes Kuehnel (1865-1928) described the new role of teachers and students according to the new vision in his book "Neubau des Rechenunterrichts" [Re-Installing the Teaching of Arithmetic] (Kuehnel 1954, 69-70, transl. E.Ch.W.) as follows:

The goal of teaching arithmetic is to provide the students with the foundations for a mathematical penetration of all things and phenomena of nature and human life ... When therefore in the enlightened educational view of our time skills appear as certainly indispensable tools and so as an unquestioned objective of teaching, however, not more than tools, it is the task of the future to consciously replace the mere concentration on skills by true mathematical education.

The main question that provides the yardstick and the orientation for the whole book can be formulated as follows: What is the both scientifically and practically founded teaching method by which we can further the development of the student in the desired way?

This formulation readily reveals the influence of the new orientation. It is not a method by which we want to instruct the student in something in a way as easy, as painless or as pleasurable as possible, be it knowledge or skills. Instructing, presenting, conveying are notions of the art of teaching of the past and have only little value for the present time; for the educational view of our time is no longer directed to plain subject matter. Of course, the student should acquire knowledge and skills also in future - we even hope more than in the past - however, we do not want to impose them on him, but he should acquire them himself. In this way also the role of the teacher is changing in every respect. Instead of delivering subject matter he will have to develop the student's abilities. This is something completely different, in particular for teaching arithmetic. For the differently formulated question for the teaching method will deprive the teacher of two instruments that in the past seemed indispensable and as marks of the highest art of teaching: presenting and forming. For compensation the teacher gets two other instruments that at first sight seem insignificant, that, however, are much more powerful: providing opportunities and stimulating individual development.

And the student is no longer tuned to passively receiving knowledge, but to actively acquiring $i t$. What characterizes the teaching method of the future is not instruction and receptivity, but organization and activity.

In the following decades this view of teaching and learning has gradually spread in many countries and found substantial support from many sides (see, for example, ATM 1967, with a wonderful preface by David Wheeler; Freudenthal 1972¹ ; Becker

\footnotetext{
${ }^{1}$ Interestingly, Hans Freudenthal had studied Kuehnel's book thoroughly.
} 
and Shimada 1997, translated from the Japanese original published in 1977; Revuz 1980, with a most remarkable title; Winter 1989).

In the early1980s Heinrich Winter, very much influenced by Hans Freudenthal, served as an advisor for a committee engaged with developing a syllabus for the primary school of the state of North Rhine-Westphalia. In the document the role of the teacher is described in Winter's unmistakable style as follows (KM 1985, transl. E.Ch.W.):

For pursuing the mission and the objectives of mathematics teaching a conception is appropriate in a particular way in which learning mathematics is considered as a constructive, inquiry-based process. This means that students should get as many opportunities as possible for self-reliant learning in all phases of the learning process:

- starting from challenging situations; stimulating the students to observe, to ask questions, to guess

- displaying a problem or a complex of problems; encouraging students' own ideas and providing support

- anchoring new knowledge in prior knowledge in manifold ways; summarizing new knowledge as clearly and concisely as possible, in some cases insisting on memorization; encouraging students to practice on their own

- discussing with students about the nature of the new knowledge and about the processes with which it has been gained (recollection), stimulating students to investigate related problems by themselves.

The role of the teacher consists of finding and offering challenging problems, providing students with conceptually rich teaching aids and productive forms of exercises and above all to establish and maintain a communication that is favorable for the learning processes of all children.

This syllabus also reflected the so-called "general mathematical objectives" that Winter had already formulated ten years previously: Mathematizing, Exploring, Explaining and Communicating (Winter 1975).

Another important innovation brought about by this syllabus is the emphasis on a balanced orientation to both applications and structure (applied and pure mathematics) that Winter had postulated in a paper on the role of mathematics for general education, in which he delineated three major objectives of mathematics teaching (Winter 1995):

(1) to perceive and understand phenomena in the world around us that concern us or should concern us, in nature, society and culture, and to do this in a way specific for mathematics,

(2) to get acquainted with mathematical structures, represented in language, symbols, pictures and formulae, and to understand them as mental creations, as a deductively ordered world of its own,

(3) to acquire problem-solving strategies (heuristic strategies) going beyond mathematics by coping with problems.

The design science approach to mathematics education has been born from the intention to assist teachers in these tasks, that is, to provide them with first-hand 
knowledge for organizing learning processes in the form of elaborated teaching units (later called substantial learning environments). These units should be explicit about how

- to introduce students into mathematical activities by which mathematical knowledge can be acquired,

- to accompany them and to provide support during their activities,

- to assist students in reporting about their observations, in formulating the patterns they have found,

- to assist students in explaining these patterns,

- to fix the knowledge that has been acquired and to summarize it in a pregnant form.

These professional interventions of teachers reflect the natural flow of any goaldirected teaching and learning of mathematics. Guy Brousseau has captured them in five "didactical situations": instruction, action, formulation, validation, and institutionalization (Brousseau 1997).

Table 1 shows the interplay between the teacher's interventions and students' activities whereby italics indicate who is taking the initiative during the situation in question (Wittmann and Müller 2017, 20).

Table 1 Brousseau's didactical situations

\begin{tabular}{l|l|l|l|l|l}
\hline & Instruction & Action & Formulation & Validation & $\begin{array}{l}\text { Institution- } \\
\text { alization }\end{array}$ \\
\hline Teacher & $\begin{array}{l}\text { Explaining the } \\
\text { objectives and } \\
\text { the } \\
\text { problem(s), } \\
\text { providing } \\
\text { students with } \\
\text { material }\end{array}$ & $\begin{array}{l}\text { Observing and } \\
\text { stimulating } \\
\text { students, if } \\
\text { necessary, } \\
\text { asking for } \\
\text { explanations }\end{array}$ & $\begin{array}{l}\text { Listening, } \\
\text { asking for } \\
\text { further } \\
\text { explanations }\end{array}$ & $\begin{array}{l}\text { Stimulating } \\
\text { explanations, } \\
\text { deepening } \\
\text { insights }\end{array}$ & $\begin{array}{l}\text { Summarizing } \\
\text { the acquired } \\
\text { knowledge in } \\
\text { a concise form }\end{array}$ \\
\hline Students & $\begin{array}{l}\text { Paying } \\
\text { attention, } \\
\text { listening, } \\
\text { asking for } \\
\text { further } \\
\text { explanations, } \\
\text { "joining in" }\end{array}$ & $\begin{array}{l}\text { Working on } \\
\text { the problems, } \\
\text { exchanging } \\
\text { information } \\
\text { with other } \\
\text { students }\end{array}$ & $\begin{array}{l}\text { Presenting } \\
\text { solutions } \text { or } \\
\text { patterns that } \\
\text { have been } \\
\text { discovered }\end{array}$ & $\begin{array}{l}\text { Explaining } \\
\text { solutions and } \\
\text { patterns by } \\
\text { taking up } \\
\text { teacher's } \\
\text { suggestions }\end{array}$ & $\begin{array}{l}\text { Listening, } \\
\text { asking for } \\
\text { further } \\
\text { explanations }\end{array}$ \\
\hline
\end{tabular}

This table is extremely useful for organizing teaching and for analyzing and evaluating lessons along the "Organization and Activity" model of learning and teachingprovided the potential inherent in mathematics is used properly.

The next section illustrates it with an example. 


\section{The Learning Environment "Calculating with Remainders"}

The book Notes on Primary Mathematics (ATM 1967) starts with the sketch of a unit ("An Addition Game") that is well suited to show how Table 1 can be brought to mathematical life. In this section this unit will be expanded into a fully-fledged learning environment. In Germany the natural place of this unit in the curriculum is the beginning of grade 5. This grade is traditionally devoted to refreshing knowledge of mental arithmetic, semiformal strategies of calculation, the standard algorithms, and the arithmetical laws from the first four years of education (that in most German states form the primary school).

Objectives: Repetition of arithmetic at the primary level in the context of a mathematical structure that goes beyond the familiar number structure and has applications on the EAN-Number and the ISBN-Number.

Mathematical background: Residue class rings

Teaching materials: Counters, dot arrays, worksheets

1. At the beginning the teacher announces that the following unit is intended to practice arithmetical skills and to explore new mathematical structures that at first sight look a bit strange but give the opportunity for creative work.

2. Introduction of the tasks

First the students are asked to solve some division problems (Fig. 3).

Based on the results and explanations of the students the teacher emphasizes that any number can be written as a multiple of 10 plus a remainder that is just the Ones digit of the number (Fig.4)

$$
\begin{aligned}
& 140: 10=\ldots, \\
& 143: 10=\ldots, \\
& 6578: 10=\ldots, \\
& 7200: 10=-\ldots, \\
& 19561: 10=\ldots
\end{aligned}
$$

Fig. 3 Divisions by 10 without remainder

$$
\begin{aligned}
& 140=14 \cdot 10 \\
& 143=14 \cdot 10+3 \\
& 6578=657 \cdot 10+8 \\
& 7200=720 \cdot 10 \\
& 19561=1956 \cdot 10+1
\end{aligned}
$$

Fig. 4 Divisions by 10 with remainder 
The students then receive the extended Hundred chart as a worksheet (Fig. 5) and use it as follows:

Each student chooses two columns of this chart and exerts additions and multiplications only with the numbers of these two selected columns. The teacher explains this rule by means of examples (Fig. 6).

3. Student work

While the students are working the teacher checks if the task has been well understood and provides support where necessary.

\begin{tabular}{|c|c|c|c|c|c|c|c|c|c|}
\hline 1 & 2 & 3 & 4 & 5 & 6 & 7 & 8 & 9 & 10 \\
\hline 11 & 12 & 13 & 14 & 15 & 16 & 17 & 18 & 19 & 20 \\
\hline 21 & 22 & 23 & 24 & 25 & 26 & 27 & 28 & 29 & 30 \\
\hline 31 & 32 & 33 & 34 & 35 & 36 & 37 & 38 & 39 & 40 \\
\hline 41 & 42 & 43 & 44 & 45 & 46 & 47 & 48 & 49 & 50 \\
\hline 51 & 52 & 53 & 54 & 55 & 56 & 57 & 58 & 59 & 60 \\
\hline 61 & 62 & 63 & 64 & 65 & 66 & 67 & 68 & 69 & 70 \\
\hline 71 & 72 & 73 & 74 & 75 & 76 & 77 & 78 & 79 & 80 \\
\hline 81 & 82 & 83 & 84 & 85 & 86 & 87 & 88 & 89 & 90 \\
\hline 91 & 92 & 93 & 94 & 95 & 96 & 97 & 98 & 99 & 100 \\
\hline 101 & 102 & 103 & 104 & 105 & 106 & 107 & 108 & 109 & 110 \\
\hline 111 & 112 & 113 & 114 & 115 & 116 & 117 & 118 & 119 & 120 \\
\hline 121 & 122 & 123 & 124 & 125 & 126 & 127 & 128 & 129 & 130 \\
\hline
\end{tabular}

Fig. 5 Extended Hundred chart

Columns with Ones digit 4 and Ones digit 7

Additions:

$44+87=131$

$17+34=51$

$64+17=81$

\section{Multiplications:}

$14 \cdot 7=98$

$27 \cdot 24=648$

$64 \cdot 47=3008$

Fig. 6 Examples of calculations 


\section{Report}

After the students have collected enough data the teacher directs the attention to the Ones digits of the results. The students report on their findings. With the teacher's support they will formulate a pattern: the Ones digits of the results depend only on the Ones digits of the summands resp. the factors.

For example, the Ones digits 3 and 7 always yield the Ones digit 0 for addition and the Ones digit 1 for multiplication.

5. Explanation of the pattern

The explanation follows immediately from the standard algorithms (Fig. 7):
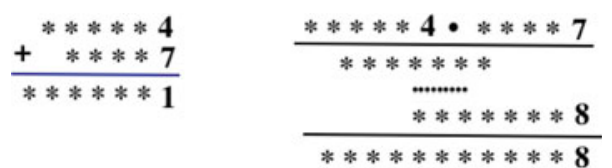

Fig. 7 Schemes of long addition and long multiplication

Both the addition and the multiplication of the Ones digits might lead to a carry. This carry and the following calculations do not affect the Ones digits. The size of the numbers does not matter.

6. Summary

The teacher summarizes the findings by telling the students that mathematicians have found it useful to "forget" the tens, hundreds, thousands, etc. and to calculate only with the Ones digits by using slightly different signs:

$$
7 \oplus 4=1
$$

In words: the Ones digit 7 additively combined with the Ones digit 4 yields the Ones digit 1.

In short: 7 plus 4 equals 1 . In this case, however, "plus" means the new sign $\oplus$.

$$
7 \odot 4=8
$$

In words: the Ones digit 7 multiplicatively combined with the Ones digit 4 yields the Ones digit 8.

In short: "7 times 4 equals 8". Again "times" here means the new sign $\odot$.

The students get a worksheet (Fig. 8) in which some results of the addition and the multiplication table for the Ones have already been entered. The teacher should take time and slowly explain how the tables have to be read and show how sums and products of Ones are entered into the table.

Only after a thorough clarification should the individual students fill in the missing entries themselves. Of course, students are allowed to cooperate, as always, and to assist each other. 


\begin{tabular}{|l|l|l|l|l|l|l|l|l|l|l|} 
& $\mathbf{0}$ & $\mathbf{1}$ & $\mathbf{2}$ & $\mathbf{3}$ & $\mathbf{4}$ & $\mathbf{5}$ & $\mathbf{6}$ & $\mathbf{7}$ & $\mathbf{8}$ & $\mathbf{9}$ \\
\hline $\mathbf{0}$ & 0 & & 2 & & & 5 & & & 8 & \\
\hline $\mathbf{1}$ & & 2 & & 4 & & & & & & 0 \\
\hline $\mathbf{2}$ & 2 & & & 5 & & 7 & 8 & & & 1 \\
\hline $\mathbf{3}$ & & & 5 & & 7 & & 9 & 0 & & \\
\hline $\mathbf{4}$ & & 5 & & 7 & & & & & & 3 \\
\hline $\mathbf{5}$ & 5 & & 7 & & 9 & & 1 & & 3 & \\
\hline $\mathbf{6}$ & & & & & & & & & & \\
\hline $\mathbf{7}$ & 7 & & & 0 & & & & 4 & & 6 \\
\hline $\mathbf{8}$ & & & 0 & & & 3 & & & & 7 \\
\hline $\mathbf{9}$ & & & & & & & & & & \\
\hline
\end{tabular}

\begin{tabular}{|l|l|l|l|l|l|l|l|l|l|l|} 
& $\mathbf{0}$ & $\mathbf{1}$ & $\mathbf{2}$ & $\mathbf{3}$ & $\mathbf{4}$ & $\mathbf{5}$ & $\mathbf{6}$ & $\mathbf{7}$ & $\mathbf{8}$ & $\mathbf{9}$ \\
\hline $\mathbf{0}$ & 0 & & 0 & & & & & & & \\
\hline $\mathbf{1}$ & & 1 & & 3 & & & & & & 9 \\
\hline $\mathbf{2}$ & 0 & & & 6 & & 0 & 2 & & & \\
\hline $\mathbf{3}$ & & & & & 2 & & 8 & & & 7 \\
\hline $\mathbf{4}$ & & & & 2 & & & & 8 & & 6 \\
\hline $\mathbf{5}$ & & & & 5 & 0 & & & 5 & & \\
\hline $\mathbf{6}$ & & 2 & & & & & & 8 & \\
\hline $\mathbf{7}$ & & 7 & & 1 & & & & 9 & & 3 \\
\hline $\mathbf{8}$ & & & 6 & & & 0 & & & & 2 \\
\hline $\mathbf{9}$ & & & & 7 & & & 4 & & & 1 \\
\hline
\end{tabular}

Fig. 8 Addition table and multiplication table modulo 10

\section{Applications}

Certainly, the students will wonder what purpose these tables are useful for and will be surprised that there is an application in their immediate environment. Both the European Article Numbers (EAN) and the International Standard Book Number (ISBN) consist of 13 digits whereby the last digit is a check digit that is determined in the following way: the first 12 digits are alternately multiplied by 1 and 3 according to the addition and multiplication table for the Ones, and then the sum of the products is determined according to the addition table of the Ones. Finally, the check digit is chosen such that it complements the sum to 0 .

Example EAN $978489582586 ?$

First the digits are multiplied alternately with 1 and 3:

$$
\begin{aligned}
& 9 \odot 1 \oplus 7 \odot 3 \oplus 8 \odot 1 \oplus 4 \odot 3 \oplus 8 \odot 1 \oplus 9 \odot 3 \oplus 5 \odot 1 \oplus 8 \odot 3 \oplus 2 \odot 1 \\
& \quad \oplus 5 \odot 3 \oplus 8 \odot 1 \oplus 6 \odot 3 .
\end{aligned}
$$

From the multiplication table for the Ones we gather the results of the products:

$$
9 \oplus 1 \oplus 8 \oplus 2 \oplus 8 \oplus 7 \oplus 5 \oplus 4 \oplus 2 \oplus 5 \oplus 8 \oplus 8 .
$$

The addition table for the Ones allows us to calculate this sum step by step:

$$
9 \oplus 1=0, \quad 0 \oplus 8=8, \quad 8 \oplus 2=0, \ldots
$$

In shorthand notation:

$9 \oplus 1 \mid$\begin{tabular}{l|l|l|l|l|l|l|l|l|l|l}
$\oplus 8$ & $\oplus 2$ & $\oplus 8$ & $\oplus 7$ & $\oplus 5$ & $\oplus 4$ & $\oplus 2$ & $\oplus 5$ & $\oplus 8$ & +8. & 7
\end{tabular}

The check digit must be 3 as $7 \oplus 3=0$.

The teacher explains this procedure by means of examples. Then the students join in to explain the check digits of some other EAN or ISBN Numbers. It is helpful to hand out a sheet with correct addition and multiplication tables for the Ones. 
At the end of this unit each student should be able to determine the check digit of the EAN number of an article bought in some shop or check the ISBN number of some of their books.

\section{Possible continuation of this learning environment}

The module 10 can be replaced by any module $m$ (see ATM 1967).

It is standard to write the numbers in schemes with $\mathrm{m}$ columns. All numbers with the same remainder under the division by $m$ then form a column. Within each column the numbers increase by $\mathrm{m}$. These columns are denoted by the remainders $1,2, \ldots, 0$. Figure 9 provides this scheme for the module 5 .

First the scheme must be investigated. The students realize that in each column the numbers increase by 5 . If a multiple of 5 is added to a number in some column the result lies in the same column. The last column contains the multiples of 5.

If counting along this scheme is accompanied by a growing array of dots the students see that all numbers in a column leave the same remainder when divided by 5 (see the "film" in Fig. 10).

The numbers with the remainder 0 are identified as the multiples of 5 that are known from the multiplication table. In the Mathe 2000 curriculum the multiples of any number are calculated by explicitly using the arithmetical laws. In this case students know already that the sum and the difference of two multiples is again a multiple and that the multiple of the multiple of a number is a multiple of that number, too.

\begin{tabular}{|c|c|c|c|c|} 
Rem. 1 & Rem. 2 & Rem. 3 & Rem. 4 & Rem. 0 \\
1 & 2 & 3 & 4 & 5 \\
6 & 7 & 8 & 9 & 10 \\
11 & 12 & 13 & 14 & 15 \\
16 & 17 & 18 & 19 & 20 \\
21 & 22 & 23 & 24 & 25 \\
26 & 27 & 28 & 29 & 30 \\
31 & 32 & 33 & 34 & 35
\end{tabular}

Fig. 9 Number table modulo 5

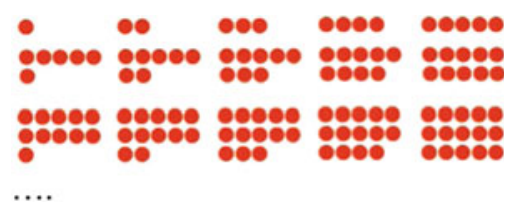

Fig. 10 Iconic representation of the number table modulo 5 
In ATM (1967) the scheme in Fig. 8 and similar schemes are investigated. The columns are denoted by letters, $A, B, C, D, E$ etc. As in the Mathe 2000 curriculum "pretty packages" play a prominent role from grade 1 , it is natural to tie in with this format. The teacher shows how "pretty packages" can be constructed with the scheme in Fig. 9. Two columns are chosen and then "pretty packages" are constructed by starting with the sum or the product of the two smallest numbers of the columns and increasing one or both numbers gradually. After each calculation the column of the result is noted. Figure 11 shows some examples:

As mentioned previously, the first objective of this learning environment is to refresh arithmetical skills. So, it is no disadvantage at all that these calculations take time. The students are free to use mental arithmetic, semiformal strategies, and standard algorithms. They are also free to choose numbers as big or as small as they want.

\begin{tabular}{|c|c|c|c|c|c|c|c|}
\hline $4=$ & & $+5=$ & Rem. 1 & $2 \cdot 4=$ & Rer & $1 \cdot 1$ & \\
\hline 8 & 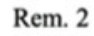 & $5=$ & Rem & $7 \cdot 4=28$ & $\mathrm{Rc}$ & $6 \cdot 1$ & en \\
\hline$t=$ & Rem. & $+10=21$ & Rem. & $12 \cdot 4$ & Rer & 66 & Rem \\
\hline $3+$ & Rem. 2 & $15=31$ & $\mathbf{R}$ & 3 & $\mathrm{R}$ & 21 & $\mathrm{em}$ \\
\hline$=2$ & Rem. 2 & $=$ & Rem. 1 & $17 \cdot 14$ & $\mathrm{R}$ & 76 & $\mathrm{em}$ \\
\hline$=32$ & em. 2 & $26+20=46$ & n. 1 & $=308$ & Rem. 3 & 1.10 & \\
\hline
\end{tabular}

Fig. 11 Calculations with fixed columns

The most difficult problem is determining the remainder of the results when the numbers get bigger. In the Mathe 2000 curriculum students learn how to decompose a number into multiples of the divisor according to their preferences and they learn the standard algorithm for division, as well as for arbitrary big divisors (see the "smart division" in Wittmann and Müller 2018, 238-240).

Of course, some calculations will be wrong. However, students will quickly guess that all results in a pretty package have the same remainder. This helps them to spot and correct mistakes. After calculating students will have much to report.

Unanimous finding: the remainders of the results do not depend on which numbers of a column have been chosen, but only the columns themselves.

The teacher shows how to fix the findings in tables similar to Fig. 8 (see Fig. 12).
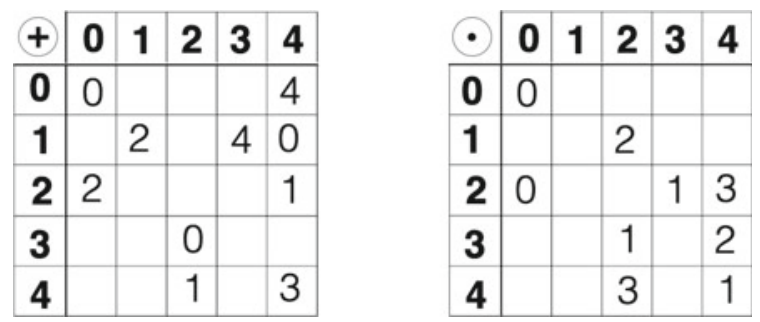

Fig. 12 Addition table and multiplication table modulo 5 
How to explain the pattern? For the module 5 the proof that the columns of the sum and the product of two numbers depend only on the columns of the summands resp. the factors can be given in a way similar to the module 10.

Example The Ones digits 2 and 7 in the column "Remainder 2" and the Ones digits 3 and 8 in the column "Remainder 3 " add up to $2+3=5,2+8=10,7+3=10$, and $7+8=15$. The results all have the Ones digit 5 or 0 . Therefore they belong to the column "Remainder 0".

The Ones digits of products with these Ones digits yield $2 \cdot 3=6,2 \cdot 8=16$, $7 \cdot 3=21$, and $7 \cdot 8=56$. So, all products have the Ones digits 1 or 6 and belong to the column "Remainder 1 ". However, it would take time to check all combinations.

The following operative proof uses the arithmetical laws and knowledge from "pretty packages". It has the advantage of covering all modules. For the module 5 the proof runs as follows:

If a summand of a sum or a factor of a product is moved up one step within a column it increases by 5 . The sum then also increases by 5 , which means it stays in the same column. The product increases by a multiple of 5, according to the distributive law. Therefore, the product also does not leave the column.

For the addition these operations can be illustrated by referring directly to counters: if 5 counters are added to a summand then the sum is increased by 5 . In the case of multiplication dot arrays render the same service. The increase of a factor of a product by 5 changes the product by a multiple of 5 (see Wittmann and Müller 2017, 71, 202-205).

For grade 5 this proof is quite appropriate, provided that the arithmetical laws have received the attention they deserve from grade 1 .

If there is enough time students could investigate other modules (ATM 1967).

The learning environment can be taken up later in the curriculum when the arithmetical laws are available in their formal setting and the operative proof can be re-formulated in the language of algebra. Substantial mathematics should be revisited on multiple occasions regardless.

The structure-genetic didactical analysis in this section demonstrates the following points:

1. What has to be taught is determined in broad terms by the syllabus. It is up to the designer to construct learning environments consistent with the syllabus that

- take up students' prior knowledge

- present problems that call for students' active participation in investigating these problems

- provide students with interesting materials for practicing skills and fostering heuristic strategies

- give students an authentic account of what mathematics is about. (see Winter's description of the role of the teacher in Sect. 1)

It is obvious that mathematics and its applications are the decisive source for design. 
2. The unit in this section starts with an assignment that leaves the individual student free space for his or her activities. First results are likely to provide feedback for the following calculations. The conjecture (discovery) of patterns leads to the desire for explanations, that is proofs. If earlier in the curriculum the designer has taken measures for introducing tools that are appropriate for formulating a proof then the teacher and the students are well prepared.

It is obvious that the whole teaching/learning process is essentially determined by the natural flow of a mathematical investigation. Brousseau's didactical situations describe the essential steps in this process. It is mathematics that provides the teacher with first-rate professional knowledge.

3. The mathematical structure that is carrying the learning environment does not only give stimuli to the teacher, but, as important, also to the students. The more experience students have acquired in past learning, the more they will be able to proceed on their own. Winter's general mathematical objectives "Mathematizing, Exploring, Explaining, Communication" are used all the time. Mathematical activities that give rise to these general mathematical objectives are the best context for learning notations, symbols, termini, expressions, and the informal language that naturally go along with doing mathematics.

It is obvious that students get essential stimuli for learning from mathematics itself.

However, the conclusions that are drawn here presuppose a certain view of mathematics. This will be clarified in the following two sections.

\section{Mathematics for Specialists and Mathematics for Teachers}

From the point of view of the mathematical specialist the structure underlying the learning environment of Sect. 2 is an elementary example of the following general construction:

One starts from the commutative ring $(\mathbb{Z},+, \cdot)$ of integers in which the following laws hold:

$(\mathbb{Z},+)$ is a commutative additive group with 0 as the neutral element, the operation - obeys the commutative and associative law, and + and - are connected by the associative law.

The set $m \mathbb{Z}$ of multiples of any number $m>1$ forms not only a subring of $(\mathbb{Z},+, \cdot)$, but it also contains all products $s \cdot t$, where $s \in \mathbb{Z}$ and $t \in m \mathbb{Z}$.

Two elements $a, b \in \mathbb{Z}$ are called equivalent, denoted by $a \equiv b$, if $a-b \in m \mathbb{Z}$. It is easy to see that this is exactly the case if $a$ and $b$ leave the same remainder when divided by $m$.

By using the existence of the neutral element 0 for addition, the existence of additive inverse elements, and the associative law for addition, it is proved that the relation $\equiv$ is a reflexive, symmetric, and transitive relation. Therefore, it is an equivalence relation that splits $\mathbb{Z}$ into disjunct equivalence classes. There are $m$ classes, denoted 
as $[0],[1], \ldots,[m-1]$ according to the possible remainders $0,1, \ldots, m-1$, under the division by $m$.

The set of these residue classes is called the residue class ring $\mathbb{Z}$ modulo $m$, written as $\mathbb{Z} / m \mathbb{Z}$. The elements of a class are called "representatives" of this class. Any of these elements or "representatives" determines the class.

For $\mathbb{Z} / m \mathbb{Z}$ two operations are derived from the operations + and - in $\mathbb{Z}$ as follows:

For any classes $[a],[b] \in \mathbb{Z} / m \mathbb{Z}$

$$
\begin{aligned}
& \text { the sum }[a] \oplus[b] \text { is defined as the class }\left[a^{\prime}+b^{\prime}\right] \\
& \text { the product }[a] \odot[b] \text { is defined as the class }\left[a^{\prime} \cdot b^{\prime}\right]
\end{aligned}
$$

where $a^{\prime}$ is an arbitrary element of $[a]$ and $b^{\prime}$ is an arbitrary element of $[b]$.

In order to show that these operations are welldefined it has to be proved that the resulting classes are independent of the choice of the representatives.

Proof Assume $a \equiv a^{\prime}$, that is $a=a^{\prime}+s \cdot m$, and $b \equiv b^{\prime}$, that is $b=b^{\prime}+t \cdot m$.

From the laws holding in $\mathbb{Z}$ we deduce

$$
\begin{gathered}
a+b=a^{\prime}+s \cdot m+b^{\prime}+t \cdot m=a^{\prime}+b^{\prime}+(s+t) \cdot m, \text { that is } \\
(a+b)-\left(a^{\prime}+b^{\prime}\right)=(s+t) \cdot m \in \mathbb{Z} . \\
a \cdot b=\left(a^{\prime}+s \cdot m\right) \cdot\left(b^{\prime}+t \cdot m\right)=a^{\prime} \cdot b^{\prime}+\left(a^{\prime} \cdot t+b^{\prime} \cdot s+s \cdot t \cdot m\right) \cdot m, \text { that is } \\
a \cdot b-a^{\prime} \cdot b^{\prime}=\left(a^{\prime} \cdot t+b^{\prime} \cdot s+s \cdot t \cdot m\right) \cdot m \in \mathbb{Z} .
\end{gathered}
$$

By definition we get $a+b \equiv a^{\prime}+b^{\prime}$ and $a \cdot b \equiv a^{\prime} \cdot b^{\prime}$. The laws holding in $(\mathbb{Z},+, \cdot)$ are transferred to the structure $(\mathbb{Z} / m \mathbb{Z}, \oplus, \odot)$ as follows: [0] is the neutral element of $\oplus,[-a]$ the inverse element of $[a]$, the associative law for $\oplus$ follows from the associative law in $(\mathbb{Z},+)$.

Proof For $a, b, c \in \mathbb{Z}$ we have

$$
\begin{aligned}
([a] \oplus[b]) \oplus[c] & =([a+b]) \oplus[c]=([(a+b)+c]=[a+(b+c)] \\
& =[a] \oplus[b+c]=[a] \oplus([b] \oplus[c]) .
\end{aligned}
$$

In a similar way the commutative law for $\oplus$ and the commutative and associative law for $\odot$ and the distribute law are derived.

Therefore $(\mathbb{Z} / m \mathbb{Z},+, \cdot)$ is a commutative ring also.

This construction can be generalized to any $\operatorname{ring} \mathbf{R}$ and a subring $\mathbf{I}$ with the property that for all $s \in \mathbf{R}$ and $t \in \mathbf{I}$ the product $s \cdot t$ belongs to $\mathbf{I}$. Such a subring is called an ideal. The arising structures are called quotient rings. For the sake of simplicity the signs + and - are also used for $\oplus$ and $\odot$.

In an analogous way quotients of other algebraic structures can be defined.

The construction of quotient structures is a powerful tool of mathematics that marks the turn to modern mathematics at the beginning of the twentieth century. It 
is far from being easily accessible and needs a long habituation (Gowers et al. 2008, 26):

Many people find the idea of a quotient somewhat difficult to grasp, but it is of major importance throughout mathematics, which is why it has been discussed in some length here.

In the context of this volume the decisive question is the following: to what extent is it necessary that teachers know the theory of residue class rings in its mathematical setting? For mathematical hardliners the answer is clear: teachers need to know it in full it as it is standard in mathematics. For them it is also clear that this knowledge is not only necessary but also sufficient for teaching any decent unit about residue class rings, even if in teaching elementary means have to be employed.

Mathematics educators would hardly agree to the second part of the statement, but many tend to agree to the first part. In Germany the formal theory of residue class rings is a firm part of courses in number theory for student teachers at secondary level and for primary student teachers with mathematics as a major subject. Even books written by mathematics educators follow the formal presentation (see, for example, Padberg 2008).

However, a closer look at this issue leads to a differentiated picture. For teachers who want to teach in the learning environment illustrated in Sect. 3 a knowledge of the theory of residue class rings is certainly necessary, however, not in its formal setting, but in a setting that uses a terminology that is meaningful for communication with students in the early secondary grades. If for a given module the numbers are represented in tables, the equivalence relation is implicitly defined by this scheme, the term "class" is replaced by "numbers in a column", and the remainders are the natural substitutes for the classes. The term "representative of a class" is superfluous. The independence of the operations from the choice of the representatives is secured by an operative proof that uses the laws of arithmetic, however, in a way that students are familiar with (see Sect. 2). The objects of calculations are not classes, but remainders.

This informal treatment of residue classes is mathematically sound and can be expanded into a theory of residue class rings beyond the formal setting (see Sect. 4). For the designer the mathematical theory is nevertheless very important as it displays the logical relationships in a concise way and shows that this structure is no impasse but finds a continuation in many parts of mathematics. It would be stupid to ignore that many learning environments are stimulated by higher mathematics. There is no doubt that the authors of ATM (1967) who designed the first learning environment in their book had full mastery of the formal representation of the theory of residue class rings. So, to know higher mathematics is a significant advantage for the designer. However, it is by far not sufficient for designing learning environments that match students' prior knowledge at various levels.

The tension between informal and formal settings of mathematics visible in this example is a general one. Wolfgang Kroll, one of the most experienced teachers and supervisors in the practical phase of teacher education in Germany, has expressed it as follows (Kroll 1997, transl. E.Ch.W.): 
Mathematics is a network of concepts and theorems that can be knotted in very different ways and captures quite different things: relationships with the real world, views, imaginations, motives, interests, meanings. As a mental activity - so should it be experienced - it also includes the processes that create mathematics. Networks that are built in a linear way according to the scheme "definition, theorem, proof" have a completely different meaning (and function!) in comparison with networks that are knotted according to other needs, with meshes sometimes wider, sometimes closer, sometimes forwards, sometimes backwards, in different colors and for different purposes.

The network knotted at the university is the "scientific system mathematics", the net knotted at school is something different, and could be called "mathematics as symbolic appropriation of reality". Therefore, mathematics at school is neither contained in mathematics at the university nor can it be easily derived from it.

Despite these differences, the network "school mathematics" and the network "university mathematics" must not be seen as contradictory. In several papers (that are referred to in some parts of this volume) John Dewey has dissolved the tension with a genetic view of mathematics and by distinguishing between two aspects of mathematics: mathematics as a research field and mathematics as a means for fostering mental growth.

Very illuminating in our context is Dewey's comment on a paper by the geometer G.B. Halsted. This comment appeared in close proximity to Dewey's great paper "The Relation of Theory to Practice in Education". Halsted, the author of a textbook on elementary geometry based on Hilbert's "Grundlagen der Geometrie", had criticized textbooks in geometry for being mathematically incorrect and insisted that textbooks should from the very beginning present "not only the truth, but the whole truth" (Dewey 1903/1977, 218). Dewey fundamentally disagreed and instead suggested to look at learning geometry as a process that advances from more intuitive, contextrelated, and applied versions of geometry to more rigorous representations (Dewey 1903/1977, 228):

These two sides, which I venture to term the psychological and the logical, are limits of a continuous movement rather than opposite forces or even independent elements ... it is a social wrong under the name of pure science to force [students who are not ready for it] into paths having next to no meaning for them, and which consequently lead next to nowhere.

It is important to understand that both sides are part of one mathematics. One side refers to research, the other one to earlier steps in the development of mathematics and to mathematical learning. From the genetic point of view, it is a mistake to consider the mathematics of specialists as the "true" manifestation of this science and to relegate school mathematics to the sidelines as "pre-mathematics". Historically, mathematics itself has developed from elementary theories, and the lower levels have carried the higher ones, not the other way round. In the same way, more elementary levels of learning that are necessarily less advanced carry the higher ones and cannot be skipped. Representations of some mathematics on a higher level cannot be imposed on students who do not have the necessary prior knowledge. It cannot be emphasized enough that mathematics at lower levels is mathematics in its own right and that the basic approach to studying mathematics is invariant over the various levels: 
Because mathematics is made by men and exists only in their minds, it must be made or remade in the mind of each person who learns it. In this sense mathematics can only be learnt by being created. We do not believe that a clear distinction can be drawn between the activities of the mathematician inventing new mathematics and the child learning mathematics which is new to him. The child has different resources and different experiences, but both are involved in creative acts (ATM 1967, preface).

Therefore, the best way to organize learning processes is to draw from the potential that is inherent in seeing mathematics as a growing organism, which requires a special approach. At a conference dedicated to clarifying the scientific status of mathematics education (or didactics of mathematics) in 1975 Trevor Fletcher answered the question of whether the teacher of mathematics is a mathematician or not in the following way (Fletcher 1975, 217):

\footnotetext{
I have come to the conclusion that the teacher of mathematics certainly needs to be a mathematician, and that he needs to be a special sort of mathematician. He needs the general mathematical background that enables him to talk on equal terms with mathematics graduates, although he does not need some of the more specialized areas of mathematics that form part of most degree courses which are devoted exclusively to the subject. He needs a broad knowledge of applications in the world outside and in other parts of the school curriculum.

In addition, the teacher needs specialist skills of his own, in the translation of mathematics from one form into another, in understanding the pattern of thinking of his pupils at various stages of development, and in understanding the relevance of structural ideas in mathematics to the teaching of it.
}

Mathematics educators who want to serve teachers at the very front of teaching must be mathematicians of the special sort described by Fletcher.

The conclusion also from this section is that mathematics if seen in its development is the most valuable source for designing learning environments and curricula and for providing teachers with basic knowledge for preparing and conducting lessons and for analyzing learning processes. In fact, it is the natural source, stands for mathematical authenticity, and is the only way to preserve the beauty of mathematics.

\section{From "Instruction and Receptivity" to "Organization and Activity" in Teacher Education}

The quotation at the beginning of this chapter consists of two parts. Its meaning is nicely supported by Heinrich Froebel's introduction into his third geometric gift: a cube divided into eight smaller cubes. Froebel suggests to the nursery school teacher to play a double role: first she should take this material into a room where nobody can disturb her and work intensively with this material herself as a learner in order to get thoroughly acquainted with it. Only then will she be in a position to slip into her role as a teacher and work with children.

In the same sense mathematics teachers should first explore a learning environment on their own without thinking about teaching. Only after they have become familiar with it they should think about how to guide students in exploring it. This access would greatly strengthen the familiarity with mental processes as fixed in Winter's general objectives. 
The mathematical education of teachers should support this approach. In his paper on "The Relationship of Theory and Practice in Education" a long chapter is devoted to the training in subject matter, in which Dewey is explicit in this respect (Dewey 1903/1977, 263):

Now the body of knowledge which constitutes the subject-matter of the student teacher must, by the nature of the case, be organized subject-matter. It is not a miscellaneous heap of separate scraps. (...) There is, therefore, method in subject-matter itself ... method of the highest order which the human mind has yet evolved, scientific method (...) Such being the case, there is something wrong in the "academic" side of professional training, if by means of it the student does not constantly get object-lessons of the finest type in the kind of mental activity which characterizes mental growth, and hence the educative process.

It should be obvious that the typical formal treatment of residue class rings that is suitable for specialists does not meet these requirements as it follows the paradigm "Instruction and Receptivity", excludes mathematical processes, and leaves little room for student teachers' activities.

What is needed instead is an introduction into this topic that is closer to the learning environment in Sect. 3. In this context the derivation of the laws in $Z / m \mathbb{Z}$ from the laws in $\mathbb{Z}$ is quite easy:

The remainder 0 is the neutral element in $Z / m \mathbb{Z}$ and its own inverse, for remainders $a \neq 0$ the remainder $m-a$ is the inverse.

Proof of the associative law for $\oplus$ in $Z / m \mathbb{Z}$ :

Let $a, b, c$ be remainders module $m$. The result of $(a \oplus b) \oplus c$ lies in the same column as the result of $(a+b)+c$ and the result of $a \oplus(b \oplus c)$ lies in the same column as the result of $a+(b+c)$. We have $(a+b)+c=a+(b+c)$ because of the associative law in $\mathbb{Z}$. Therefore,

$$
(a \oplus b) \oplus c=a \oplus(b \oplus c) .
$$

In the same way the commutative law for $\oplus$, the commutative and associative law for $\odot$, and the distributive law for $\oplus$ and $\odot$ can be derived.

Within this setting student teachers are given free space to determine the addition and multiplication tables for various modules, to compare the multiplication tables, and to discover similarities and differences. They could, for example, discover that for some modules all products of a remainder $\neq 0$ with the other remainders are different, while for other modules there are remainders $\neq 0$ for which the product is 0 , for example, in the case of the module 10 , where $5 \odot 2=0$. In a formal treatment these phenomena would be done away by a dry proof of the theorem that in case of a module $m$ that is a prime number the ring $(\mathbb{Z} / m \mathbb{Z}, \oplus, \odot)$ is a field.

In a course for teachers it would make sense to connect this topic to place value systems with bases different from 10 . This again would open up room for investigations. For the base 5-system the proof of the dependence of sums or products only from the columns would work exactly as in the base 10-system. And this could be transferred to other place value systems.

For special multiplication tables the students could investigate which remainders are squares of others: this would give the teacher a chance to mention the research by Gauss and others about the so-called reciprocity law. 
In a course of this kind it would also make sense to look at examples where knowledge about residue class rings is applied for solving problems. Elementary number theory is full of such examples that are an important enrichment of the theory.

Mathematical courses that are related to teaching are highly accepted by student teachers. They help them to see, appreciate, and use the educational and practical resources inherent in mathematics. Such courses also contribute greatly to developing a positive attitude towards the subject. For this reason, they are the key to real progress in mathematics teaching, and this applies to all levels. The design science approach matters to teacher education also.

\section{References}

Association of Teachers of Mathematics (ATM): Notes on Primary Mathematics. Cambridge University Press, Cambridge (1967) (translated into German in 1970)

Becker, J., Shimada, S.: The Open-ended Approach. A New Proposal for Teaching Mathematics. NCTM, Reston (1997). (translated from the Japanese original from 1977)

Brousseau, G.: Theory of Didactical Situations in Mathematics. Kluwer, Boston (1997)

de Garmo, Ch.: Herbart and the Herbartians. University Press of the Pacific, Honolulu (2001)

Dewey, J.: The Logical and the Psychological in Teaching Geometry. In: Boydston, J.A. (ed.) The Middle Works 1899-1924, vol. 3. SIU Press, Carbondale (1903/1977)

Dewey, J.: The Relation of Theory to Practice in Education. In: Boydston, J.A. (ed.) The Middle Works 1899-1924, vol. 3, pp. 249-272. SIU Press, Carbondale (1903/1977)

Elmore, R.F.: The politics of education reform. Issues in Science and Technol. 14 (Fall 1997)

Fletcher, T.: Is the teacher of mathematics a mathematician or not? In: Bauersfeld, H., et al. (eds.) Proceedings of the Conference on Tendencies and Problems of Teacher Education in Mathematics, vol. 6, pp. 203-218. Schriftenreihe des IDM, Bielefeld (1975)

Gowers, T., et al.: The Princeton Companion to Mathematics. Princeton University Press, Princeton (2008)

KM: Kultusminister des Landes NRW (Hg.). Richtlinien und Lehrpläne für die Grundschule in Nordrhein-Westfalen. Mathematik, Köln (1985)

Kroll, W.: Thesen zur gymnasialen Mathematiklehrerausbildung. In: Biehler, R. und Jahnke, H.N. (Hg.), Mathematische Allgemeinbildung in der Kontroverse. Universität Bielefeld, Institut für Didaktik der Mathematik. Occasional paper 163, pp. 84-88 (1997)

Kuehnel, J.: Neubau des Rechenunterrichts. Klinkhardt, Bad Heilbrunn (1954)

Padberg, F.: Elementare Zahlentheorie. Springer Spektrum, Wiesbaden (2008)

Revuz, A.: Est-il-impossible d'enseigner les mathématiques?. Presses Universitaires de France, Paris (1980)

Winter, H.: Entdeckendes Lernen im Mathematikunterricht. Springer Spektrum, Wiesbaden $(1989 / 2016)$

Winter, H.: Allgemeine Lernziele für den Mathematikunterricht. In: Reprinted: Mueller, G.N., Selter, C., Wittmann, E.C. (ed.) Zahlen, Muster und Strukturen. Spielräume für aktives Lernen und Üben. Stuttgart, Klett (1975/2012)

Winter, H.: Mathematikunterricht und Allgemeinbildung. Mitteilungen der Gesellschaft der Didaktik der Mathematik 6, 37-46 (1995)

Wittmann, E.C., Müller, G.N.: Handbuch produktiver Rechenübungen. Band 1: Vom Einspluseins zum Einmaleins. Stuttgart und Seelze, Klett/Kallmeyer (2017)

Wittmann, E.C., Müller, G.N.: Handbuch produktiver Rechenübungen. Band 2: Halbschriftliches und schriftliches Rechnen. Stuttgart und Seelze, Klett/Kallmeyer (2018) 


\section{Comments and Some Personal Remarks on the Papers in Chapters 2-14}

In addition to the general background described in this chapter it seems appropriate to say a few words about the origin of each paper and the context in which it was written.

Chapter 2: Teaching Units as the Integrating Core of Mathematics Education. Educational Studies in Mathematics 15 (1984), 25-36.

This paper is a translation of the German original

Unterrichtsbeispiele als integrierender Kern der Mathematikdidaktik. Journal für Mathematik-Didaktik 3 (1982), 1-18.

that was based on a plenary lecture in Darmstadt in 1981 at the annual meeting of mathematics educators from German-speaking countries.

It was not the first paper of mine on the design science approach. In 1974 there was a lively discussion on the scientific status of mathematics education to which I had contributed the article "Didaktik der Mathematik als Ingenieurwissenschaft" ["Didactics of Mathematics as Engineering"], Zentralblatt für Didaktik der Mathematik 74/3, 119-121. This article was just a first attempt in this direction. The later paper of 1984 presented the idea more clearly, even if the terminology was still in a preliminary state, as well as the diagram (Fig. 1).

Chapter 3: Clinical Interviews Embedded in the "Philosophy of Teaching Units"A Means of Developing Teachers' Attitudes and Skills. In: Christiansen, B. (ed.), Systematic Cooperation Between Theory and Practice in Mathematics Education, Mini-Conference at ICME 5, Adelaide 1984. Copenhagen: Royal Danish School of Education, Dept. of Mathematics 1985, pp. 18-31.

This paper was inspired by a sabbatical leave in Switzerland in 1974 where I had a chance to attend Jean Piaget's Monday seminars. Although at that time my main interest was devoted to the formalization of Piaget's concept of grouping, I noticed that the research method used by the members of the Centre d'épistémologie génétique was very well suited for developing the attitudes that characterize a good teacher. The paper gives an account of a course that right after my return from Geneva was firmly integrated into our teacher education program. The course consisted of two parts: in part 1 the basics of Jean Piaget's genetic epistemology were given (see Wittmann, E.Ch., Mathematisches Denken im Vor- und Grundschulalter [The Development of Mathematical Thinking at the Pre-school and primary level]. Wiesbaden. Vieweg 1982); in part 2 the student teachers conducted clinical interviews, documented them, and presented the results in a seminar. In retrospect the participants evaluated this course highest in the whole program. Again, the terminology in this paper is preliminary. What now is called the "design science approach" appears in the paper (and already in the previous paper) as "Philosophy of Teaching Units". 
Chapter 4: The Mathematical Training of Teachers from the Point of View of Education. Journal für Mathematik-Didaktik 10 (1989), 291-308.

My first years in teacher education coincided with the heyday of "New Math", a movement that I had rejected from the very beginning. The pressure at that time to be "mathematically correct" was enormous. It was not easy to get rid of the formats of courses that I had been living with for a decade during my study of mathematics and my years in a department of mathematics. I consider my book Elementargeometrie und Wirklichkeit [Elementary Geometry and Reality] (Wiesbaden: Vieweg 1987), as a personal breakthrough that was reflected in Chap. 4 , originally presented as a survey lecture at ICME 6, Budapest 1988. When preparing this paper, it occurred to me that informal representations are crucial for unfolding the resources for teaching that are inherent in mathematics. The geometry book was also an attempt to mix structure and applications in mathematical courses.

Chapter 5: When is a proof a proof? Bulletin de la Sociétè Mathématique de Belgique, Série A, Tome XLII (1990), 1542.

The German original

Wann ist ein Beweis ein Beweis? In: Bender, P. (Hrsg.), Mathematikdidaktik:

Theorie und Praxis. Festschrift für Heinrich Winter. Berlin 1988, S 237-257

was written in collaboration with Gerhard Mueller and dedicated to Heinrich Winter on the occasion of his sixtieth birthday.

The paper has been another decisive step in getting rid of the rigid bonds of formal mathematics. The documents included in the paper show that it has not been easy for student teachers to accept informal proofs as they had been "drilled" in formal presentations at school. In 1988 I attended a conference at the island of Samos, the birthplace of Pythagoras, and presented this paper. In the very first row, Andrew Gleason, one of the four mathematicians who contributed to solving Hilbert's fifth problem, was carefully listening to my talk. As he didn't say anything in the discussion, I asked him afterwards if he would agree to these proofs, to which he answered: "Of course, why do you ask me?". One year later, when I presented the same paper at a conference of the German Association of Teachers of Mathematics and Science (MNU) in Darmstadt many participants openly disagreed with my message. In the last mail I received from Hans Freudenthal in spring 1990 he complained of the stubbornness of German gymnasium teachers (my former colleagues!).

Chapter 6: Mathematics Education as a "Design Science". Educational Studies in Mathematics 29 (1995), 355-374.

In 1987 Gerhard Mueller and I had collected enough experience in our courses in mathematics and mathematics education for student teachers and thought it appropriate to found the project Mathe 2000 and to explicitly base it on the design science approach. After finishing our work on the two volumes of the Handbuch produktiver Rechenübungen [Handbook for practicing skills in a productive way], published in 1990 and 1992, it seemed about time to re-assure ourselves about our approach. The result was the paper 
Mathematikdidaktik als "design science”. Journal für Mathematik-Didaktik 13 (1992), 55-70.

When I was invited for a plenary presentation at the ICMI-Study Conference on "Mathematics Education as a Research Domain. A Search for Identity", chaired by Anna Sierpinska and Jeremy Kilpatrick, in Washington, D.C. in 1994, I presented the English translation of this paper that was also published in the ICMI-Study.

In comparison with the paper in Chap.2, this version of the design science approach is much more differentiated in many respects. Above all, mathematics education is described as a "systemic-evolutionary" design science surrounded by a series of related disciplines (see Fig. 1). There is also progress in seemingly tiny things. For example, the original representation of arithmogons (Fig. 2) had been changed (Fig. 2) in order to facilitate the use of counters. However, the term "teaching units" was retained.

From that time on, my courses on mathematics education took on the following format. In the first $45 \mathrm{~min}$ of a lecture I presented five teaching units on a topic that incorporated a theoretical principle, and in the second $45 \mathrm{~min}$ I explained this principle. In a follow-up seminar $(1.5 \mathrm{~h})$ the participants were given worksheets that stimulated activities for deepening their understanding of the topic. The acceptance of these courses by student teachers was very high, and I cannot but recommend the format.

Chapter 7: Designing Teaching: The Pythagorean Theorem. In: Cooney, Th. P. (ed.), Mathematics, Pedagogy, and Secondary Teacher Education. Portsmouth, NH: Heineman 1996, 97-165.

In the early 1990s my colleague Georg Schrage and I were invited by Tom Cooney, at that time professor at one of the leading American centers of mathematics education in Athens/Ga., to join an NSF project that was aimed at bridging the gap between mathematics, mathematics education, and the teaching practice. This project gave me a chance to demonstrate the main method of the design science approach, later called structure-genetic didactical analysis, in some detail, including mathematical analyses, clinical interviews, the design of lessons, and theoretical considerations.

The style of the paper differs from that of the other papers due to the objective of the NSF project: to include tasks that can directly be used in teacher education. As teacher education is a focus in this volume, the style has been maintained.

Chapter 8: Standard Number Representations in Teaching Arithmetic. Journal für Mathematik-Didaktik 19 (1998) 2/3, 149-178.

While working on the "Handbuch produktiver Rechenübungen", a grammar of nonsymbolic representations for arithmetic had been developing almost by itself. The paper in Chap. 8 is the summary of our experiences during this work. In the new edition of the "Handbuch" (2017/2018) the conception is carried a step further and connected with the notion of operative proof in a consistent way. The recent software "Plättchen \& Co. digital" [Counters \& Co. digitally] contains digital versions of most of the teaching aids listed in this paper. 
Chapter 9: Developing mathematics education in a systemic process. Educational Studies in Mathematics 48 (2002), 1-20.

In this paper, a plenary lecture at ICME 9, the design science approach was further elaborated with respect to systemic boundary conditions. One section is devoted to teacher education.

Chapter 10: The Alpha and Omega of Teacher Education: Stimulating Mathematical Activities. In: Holton, D., Teaching and Learning at University Level. An ICMI Study. Dordrecht: Kluwer Academic Publishers 2002, 539-552.

While in Chap. 4 a new conception of mathematical courses for teachers is sketched in broad lines, the paper in Chap. 10 describes a format for these courses in detail. Similar to my courses on mathematics education, this format also includes two parts: the first organizes student teachers' activities on a series of topics, and the second includes a systematic presentation of these topics.

As mentioned in the paper, a group of mathematics educators has joined together in writing a book, "Arithmetik als Prozess" [Arithmetic as a Process], based on this format. This book was intended as the first volume of a series, "Elementary Mathematics as a Process", that, however, has not been continued to date. I think it would be promising to restart this project at the international level as a joint venture of mathematicians and mathematics educators.

Chapter 11: Operative Proofs in School Mathematics and Elementary Mathematics.

Translated from the German original

Operative Beweise in der Schul- und Elementarmathematik. mathematica didactica 37, H. 2 (2014), 213-232.

Operative proofs that are inspired by the "operative principle" have been cultivated by quite a number of German mathematics educators. This type of proof is already discussed in some of the previous papers, and in some length in Chap. 7. In Chap. 11 the notion of operative proof is elaborated on in some detail and illustrated by typical examples. In the new edition of the "Handbuch" 2017/2018 operative proofs are developed systematically from grade 1 , in line with standard representations.

Chapter 12: Collective Teaching Experiments: Organizing a Systemic Cooperation Between Reflective Researchers and Reflective Teachers in Mathematics Education. In: Nührenbörger, M. et al. (2016). Design Science and its Importance in the German Mathematics Educational Discussion. (S. 26-34) Rotterdam: Springer Nature.

This short paper presented at ICME 13 expands on the systemic constraints of teaching by essentially referring to the work of Donald Schön. The paper introduces the idea of "collective teaching experiments" stimulated by the Japanese lesson studies. In the new "Handbuch" 2017/2018 proposals for such experiments are made for teaching arithmetic. 
Chapter 13: Structure-genetic Didactical Analyses-Empirical Research "of the First Kind”. In: Błaszczyk, P. \& Pieronkiewicz, B. (eds.), Mathematical Transgressions 2018. Kraków: Universitas, 133-150.

This paper, a plenary paper presented at a conference in Cracow in 2015, describes the main research method of the design science approach, the structure-genetic didactical analysis, and shows that this method also helps to disclose empirical evidence about the feasibility of learning environments. The second part of the title is in no sense intended as a provocation. It simply states that mathematics educators have always included experiences from their teaching practice or that of teachers they were in contact with.

Chapter 14: Understanding and Organizing Mathematics Education as a Design Science. Origins and New Developments. Hiroshima Journal of Mathematics Education 12 (2019), 1-20.

This paper is based on a plenary lecture at the annual conference of the Japanese Academic Society of Mathematics Education, Hiroshima 2017. All aspects that are discussed in this chapter are included, and in many places references are made to the new "Handbuch" 2017/2018 and to the "Book of Numbers". In Fig. 1 the related disciplines have been re-ordered. The disciplines on the left side are more closely connected to mathematics education than those on the right side. New in the picture, on the left side, is "semiotics". This is due to Willi Doerfler's epochal work in this area. His paper "Wieso kann man mit abstrakten Objekten rechnen? [How is it possible to calculate with abstract objects?]", quoted in Chap. 8, has been an eye-opener for me.

Erich Ch. Wittmann

Open Access This chapter is licensed under the terms of the Creative Commons Attribution 4.0 International License (http://creativecommons.org/licenses/by/4.0/), which permits use, sharing, adaptation, distribution and reproduction in any medium or format, as long as you give appropriate credit to the original author(s) and the source, provide a link to the Creative Commons license and indicate if changes were made.

The images or other third party material in this chapter are included in the chapter's Creative Commons license, unless indicated otherwise in a credit line to the material. If material is not included in the chapter's Creative Commons license and your intended use is not permitted by statutory regulation or exceeds the permitted use, you will need to obtain permission directly from the copyright holder.

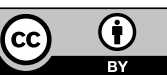

